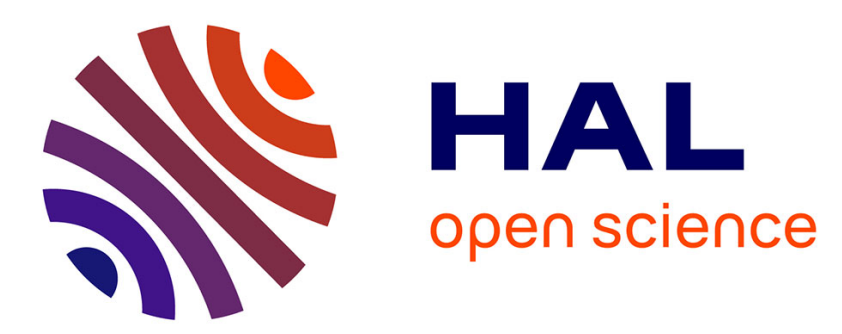

\title{
Sensorless Indirect Stator Field Orientation Speed Control for Single-Phase Induction Motor Drive
}

Mohamed Jemli, Hechmi Ben Azza, Mohamed Boussak, Moncef Gossa

\section{To cite this version:}

Mohamed Jemli, Hechmi Ben Azza, Mohamed Boussak, Moncef Gossa. Sensorless Indirect Stator Field Orientation Speed Control for Single-Phase Induction Motor Drive. IEEE Transactions on Power Electronics, 2009, 24 (6), pp.1618-1627. hal-00433490

\section{HAL Id: hal-00433490 https://hal.science/hal-00433490}

Submitted on 19 Nov 2009

HAL is a multi-disciplinary open access archive for the deposit and dissemination of scientific research documents, whether they are published or not. The documents may come from teaching and research institutions in France or abroad, or from public or private research centers.
L'archive ouverte pluridisciplinaire HAL, est destinée au dépôt et à la diffusion de documents scientifiques de niveau recherche, publiés ou non, émanant des établissements d'enseignement et de recherche français ou étrangers, des laboratoires publics ou privés. 


\title{
Sensorless Indirect Stator Field Orientation Speed Control for Single-Phase Induction Motor Drive
}

\author{
Mohamed Jemli, Hechmi Ben Azza, Mohamed Boussak, Senior Member, IEEE, and Moncef Gossa
}

\begin{abstract}
The industrial requirements for the control of an induction machine without a mechanical sensor continue to be of interest, as evidenced by the most recent publications. The focus is on improvements of control without a mechanical sensor. A new method for the implementation of a sensorless indirect stator-fluxoriented control (ISFOC) of a single-phase induction motor (SPIM) drive is proposed in this paper. The proposed method of rotor speed estimation is based only on the measurement of the main and auxiliary windings stator currents and that of a reference $q$-axis current generated by the control algorithm. The error of the measured $q$ axis current from its reference value feeds the proportional plus integral controller, the output of which is the estimated slip angular frequency. Experimental results for sensorless ISFOC speed control of a SPIM drive are presented and analyzed using a dSPACE system with DS1104 controller board based on the digital signal processor TMS320F240. Digital simulation and experimental results are presented to show the improvement in performance of the proposed sensorless algorithm.
\end{abstract}

Index Terms-Indirect stator-flux-oriented control, sensorless vector control, single-phase induction motor, speed estimation.

\section{INTRODUCTION}

$\mathbf{S}$ INGLE-PHASE induction motors (SPIM) are traditionally used in constant speed home appliances, usually in locations where only single-phase energy supply is available without any type of control strategy. They are found in air conditioners, washers, dryers, industrial machinery, fans, blowers, vacuum cleaners, and many other applications. Variable speed controls of electrical motors are widely employed in industrial applications because of the obvious energy-saving benefits. The cost reduction and high efficiency of power electronic and microelectronics devices are motivating to implement a SPIM drives in both industrial and domestic applications.

During recent years, many research laboratories have focussed on variable-speed drives, especially for the SPIM, and major improvements have been achieved. The availability of

Manuscript received October 17, 2008; revised December 12, 2008 and January 23, 2009. Current version published June 10, 2009. Recommended for publication by Associate Editor J. O. Ojo.

M. Jemli, H. B. Azza, and M. Gossa are with the Unité de Recherche en Commande, Surveillance et Sûreté de Fonctionnement des Systèmes (C3S), Equipe Développement des Systèmes Electrotechniques (DES), Ecole Supérieure des Sciences et Techniques de Tunis (ESSTT), Tunis 1008, Tunisia (e-mail: mohamed.jemli@isetr.rnu.tn; benazzahechmi@ voila.fr; Moncef.Gossa@esstt.rnu.tn).

M. Boussak is with the Laboratoire des Sciences de l'Information et des Systèmes (LSIS), UMR CNRS 6168, Centrale Marseille Recherche et Technologies (CMRT), Ecole Centrale Marseille (ECM), Technopôle Château Gombert, 13451-Marseille Cedex 20, France (e-mail: mohamed.boussak@ ec-marseille.fr).

Color versions of one or more of the figures in this paper are available online at http://ieeexplore.ieee.org.

Digital Object Identifier 10.1109/TPEL.2009.2014867 low-cost static converters makes possible the economic use of energy and improvement of the quality of the electromagnetic torque in SPIM [1]-[3]. They are three power electronic converter topologies of two-phase inverters for SPIM: two-leg, three-leg, and four-leg inverters. In recent years, the topology with three-leg two-phase with six-transistor bridge voltage source inverter for SPIM drive systems has been preferred by many researchers compared to the other topologies [1]-[13]. This suitable topology to supply the SPIM with two-orthogonal voltages system is cheaper than that of the four-leg inverter, and it gives a better performance in terms of harmonic distortion of the output voltage when compared to that of the two-leg inverter.

Nowadays, field-oriented controlled (FOC) induction motors are widely adopted to obtain high-dynamic performance in drive systems. The FOC represents a better solution to satisfy industrial requirements. The asymmetry of the SPIM has an important impact on the design of the control strategies. However, the stator flux model requires appropriate variable changes [5]. The drawback of this method is that the rotor speed of the SPIM must be measured, which requires a speed sensor. A sensorless system where the speed is estimated instead of measured would considerably reduce the cost and complexity of the drive system.

In the existing literature, many approaches have been suggested for sensorless vector speed control of SPIM drives in [14]-[17]. Some suggested methods for speed estimation using a machine model fed by stator quantities are parameter dependent; therefore, parameter errors can degrade speed control performance [18]. In paper [14], the authors evaluate a sensorless indirect rotor FOC in which the rotor flux vector frequency is estimated directly from measurable stator currents and voltages but is dependent on SPIM parameters. The sensorless speed control strategy using MRAS techniques is based on the comparison between the outputs of two estimators when motor currents and voltages must still be measured [6], [19]. The MRAS algorithm sensorless speed vector control of threephase induction motor drive is sensitive to resistance variation [20].

In this paper, we propose a contribution to the issue of speed sensorless indirect stator-flux-oriented control (ISFOC) of SPIM drive based on [18]. The published paper [18] investigates the sensorless speed control of three-phase induction motor drive. The SPIM model equations are more complex than that of the three-phase induction machines, because the main and auxiliary stator windings have different resistances and inductances. However, the use of field orientation control for an unbalanced single-phase machine requires special attention, 
because the mathematical model for this type of machine is similar to that of an asymmetrical two-phase machine. Moreover, particular converter topology and control are used to supply the SPIM based on three-leg to generate two-phase voltage source inverter in which sinusoidal pulsewide modulation (PWM) is applied.

The estimated speed is obtained only from the measurement of the main and auxiliary windings stator currents and that of a reference $q$-axis current generated by the control algorithm. A speed estimation method is proposed to overcome the problems of system complexity and cost. Simulation and experimental results are presented to demonstrate the main characteristics of the proposed drive system. The sensorless speed control algorithm is employed in this work and is implemented at rated, low, and zero speed operation.

\section{SPIM MODEL}

The dynamic model for the single-phase induction machine in a stationary reference frame can be described by the following equations:

$$
\begin{aligned}
v_{s d}^{s} & =R_{s d} i_{s d}^{s}+\frac{d \phi_{s d}^{s}}{d t} \\
v_{s q}^{s} & =R_{s q} i_{s q}^{s}+\frac{d \phi_{s q}^{s}}{d t} \\
0 & =R_{r} i_{r d}^{s}+\frac{d \phi_{r d}^{s}}{d t}+\omega_{r} \phi_{r q}^{s} \\
0 & =R_{r} i_{r q}^{s}+\frac{d \phi_{r q}^{s}}{d t}-\omega_{r} \phi_{r d}^{s} \\
\phi_{s d}^{s} & =L_{s d} i_{s d}^{s}+M_{s r d} i_{r d}^{s} \\
\phi_{s q}^{s} & =L_{s q} i_{s q}^{s}+M_{s r q} i_{r q}^{s} \\
\phi_{r d}^{s} & =L_{r} i_{r d}^{s}+M_{s r d} i_{s d}^{s} \\
\phi_{r q}^{s} & =L_{r} i_{r q}^{s}+M_{s r q} i_{s q}^{s} \\
T_{e} & =n_{p}\left(M_{s r q} i_{s q}^{s} i_{r d}^{s}-M_{s r d} i_{s d}^{s} i_{r q}^{s}\right)
\end{aligned}
$$

where $v_{s d}^{s}, v_{s q}^{s}, i_{s d}^{s}, i_{s q}^{s}, \phi_{s d}^{s}, \phi_{s q}^{s}, \phi_{r d}^{s}$, and $\phi_{r q}^{s}$ are the d-q axes voltages, currents, and fluxes of the stator and rotor in the stator reference frame; $L_{s d}, L_{s q}, L_{r}, M_{s r d}$, and $M_{s r q}$ denote the stator and rotor self and mutual inductances; $R_{s d}, R_{s q}$, and $R_{r}$ denote $d-q$ axes stator and rotor resistances; and $\omega_{r}, T_{e}$, and $n_{p}$ are the rotor angular frequency, the electromagnetic torque, and the pole pairs.

Equations (1)-(8) present the model of an asymmetrical twophase machine due to the unequal resistances and inductances of the main and auxiliary windings. This asymmetry causes an oscillating term in the electromagnetic torque [1]. As was done in [5] to drive the symmetrical model, here too, the mutual inductances will be employed to define a transformation for the stator variables. This transformation is given by

$$
\left[\begin{array}{l}
i_{s d}^{s} \\
i_{s q}^{s}
\end{array}\right]=T\left[\begin{array}{l}
i_{s d 1}^{s} \\
i_{s q 1}^{s}
\end{array}\right], \quad\left[\begin{array}{c}
v_{s d}^{s} \\
v_{s q}^{s}
\end{array}\right]=T^{-1}\left[\begin{array}{c}
v_{s d 1}^{s} \\
v_{s q 1}^{s}
\end{array}\right]
$$

and

$$
\left[\begin{array}{l}
\phi_{s d}^{s} \\
\phi_{s q}^{s}
\end{array}\right]=T^{-1}\left[\begin{array}{l}
\phi_{s d 1}^{s} \\
\phi_{s q 1}^{s}
\end{array}\right]
$$

where

$$
T=\left[\begin{array}{ll}
1 & 0 \\
0 & k
\end{array}\right] \quad \text { and } \quad k=\frac{M_{s r d}}{M_{s r q}} .
$$

Using (1)-(10), the new mathematical model of the SPIM in the stator reference frame can be described by the following equations:

$$
\begin{aligned}
v_{s d 1}^{s} & =R_{s d} i_{s d 1}^{s}+\frac{d \phi_{s d 1}^{s}}{d t} \\
v_{s q 1}^{s} & =R_{s d} i_{s q 1}^{s}+\frac{d \phi_{s q 1}^{s}}{d t}+\left(k^{2} R_{s q}-R_{s d}\right) i_{s q 1}^{s} \\
0 & =R_{r} i_{r d}^{s}+\frac{d \phi_{r d}^{s}}{d t}+\omega_{r} \phi_{r q}^{s} \\
0 & =R_{r} i_{r q}^{s}+\frac{d \phi_{r q}^{s}}{d t}-\omega_{r} \phi_{r d}^{s} \\
\phi_{s d 1}^{s} & =L_{s d} i_{s d 1}^{s}+M_{s r d} i_{r d}^{s} \\
\phi_{s q 1}^{s} & =L_{s d} i_{s q 1}^{s}+M_{s r d} i_{r q}^{s}+\left(k^{2} L_{s q}-L_{s d}\right) i_{s q 1}^{s} \\
\phi_{r d}^{s} & =L_{r} i_{r d}^{s}+M_{s r d} i_{s d 1}^{s} \\
\phi_{r q}^{s} & =L_{r} i_{r q}^{s}+M_{s r d} i_{s q 1}^{s} \\
T_{e} & =n_{p} M_{s r d}\left(i_{s q 1}^{s} i_{r d}^{s}-i_{s d 1}^{s} i_{r q}^{s}\right) .
\end{aligned}
$$

\section{INDIRECT STATOR-FLUX-ORIENTED CONTROL}

Using (15), (16), and (19), electromagnetic torque as a function of stator fluxes and stator currents can be written as

$$
T_{e}=n_{p}\left(\phi_{s d 1}^{s} i_{s q 1}^{s}-\phi_{s q 1}^{s} i_{s d 1}^{s}+\Delta T\right)
$$

where $\Delta T=\left(k^{2} L_{s q}-L_{s d}\right) i_{s q 1}^{s} i_{s d 1}^{s}$.

In the same way, using (13)-(18), we can determine the dynamic model that relates the stator flux to the stator currents.

$$
\begin{aligned}
& \frac{d \phi_{s d 1}^{s}}{d t}+\frac{1}{\tau_{r}} \phi_{s d 1}^{s}+\omega_{r} \phi_{s q 1}^{s} \\
& =\frac{L_{s d}}{\tau_{r}} i_{s d 1}^{s}+\sigma_{d} L_{s d} \frac{d i_{s d 1}^{s}}{d t}+\omega_{r} k^{2} \sigma_{q} L_{s q} i_{s q 1}^{s} \\
& \frac{d \phi_{s q 1}^{s}}{d t}+\frac{1}{\tau_{r}} \phi_{s q 1}^{s}-\omega_{r} \phi_{s d 1}^{s} \\
& \quad=k^{2} \frac{L_{s q}}{\tau_{r}} i_{s q 1}^{s}+k^{2} \sigma_{q} L_{s q} \frac{d i_{s q 1}^{s}}{d t}-\omega_{r} \sigma_{d} L_{s d} i_{s d 1}^{s}
\end{aligned}
$$

where

$$
\sigma_{d}=1-\frac{M_{s r d}^{2}}{L_{s d} L_{r}} \quad \sigma_{q}=1-\frac{M_{s r q}^{2}}{L_{s q} L_{r}} \quad \tau_{r}=\frac{L_{r}}{R_{r}} .
$$

The vector model for the stator-flux control written for an arbitrary frame (denoted by the superscript $a$ ) using (22) and 
(23) are given by

$$
\begin{aligned}
& \frac{d \phi_{s 1}^{a}}{d t}+\frac{1}{\tau_{r}} \phi_{s 1}^{a}+j\left(\omega_{a}-\omega_{r}\right) \phi_{s 1}^{a} \\
& \quad=\frac{L_{s d}}{\tau_{r}} i_{s 1}^{a}+\sigma_{d} L_{s d} \frac{d i_{s 1}^{a}}{d t}+j\left(\omega_{a}-\omega_{r}\right) \sigma_{d} L_{s d} i_{s 1}^{a}+\varsigma_{s}^{a}
\end{aligned}
$$

where

$$
\begin{aligned}
\phi_{s 1}^{a} & =\phi_{s d 1}^{a}+j \phi_{s q 1}^{a}=\left(\phi_{s d 1}^{s}+j \phi_{s q 1}^{s}\right) e^{-j \delta_{a}} \\
i_{s 1}^{a} & =i_{s d 1}^{a}+j i_{s q 1}^{a}=\left(i_{s d 1}^{s}+j i_{s q 1}^{s}\right) e^{-j \delta_{a}} \\
\varsigma_{s}^{a} & =\left(k^{2} L_{s q}-L_{s d}\right)\left[\left(\omega_{r}+j \frac{1}{\tau_{r}}\right) i_{s q 1}^{s}+j \frac{d i_{s q 1}^{s}}{d t}\right] e^{-j \delta_{a}} .
\end{aligned}
$$

We choose a reference frame linked to the stator flux, so that the $d$-axis coincides with the desired direction of the stator flux $\left(\phi_{s d 1}=\phi_{s 1}\right.$ and $\left.\phi_{s q 1}=0\right)$. Therefore, in this synchronous rotating reference (denoted by the superscript $s f$ ), the expression (23) can be decomposed into two equations.

$$
\begin{aligned}
\frac{d \phi_{s 1}}{d t}+\frac{1}{\tau_{r}} \phi_{s 1} & =\frac{L_{s d}}{\tau_{r}} i_{s d 1}^{s f}+\sigma_{d} L_{s d} \frac{d i_{s d 1}^{s f}}{d t}-\omega_{s l} \sigma_{d} L_{s d} i_{s q 1}^{s f}+\varsigma_{d}^{s f} \\
\omega_{s l} \phi_{s 1} & =\frac{L_{s d}}{\tau_{r}} i_{s q 1}^{s f}+\sigma_{d} L_{s d} \frac{d i_{s q 1}^{s f}}{d t}+\omega_{s l} \sigma_{d} L_{s d} i_{s d 1}^{s f}+\varsigma_{q}^{s f}
\end{aligned}
$$

where

$$
\begin{array}{ll}
\omega_{s l}=\omega_{s}-\omega_{r} & \text { slip angular frequency } \\
\omega_{s} & \text { synchronous angular frequency } \\
\phi_{s 1} & \text { stator-flux magnitude. }
\end{array}
$$

It is noteworthy that the model of the stator flux in (24) and (25) and the expression of the torque in (20) present additional terms $\left(\varsigma_{d}^{s f}, \varsigma_{q}^{s f}\right.$, and $\left.\Delta T\right)$ that represent the asymmetry of the machine. Note that these terms depend on $\left(k^{2} L_{s q}-L_{s d}\right)$. Considering that $\varsigma_{d}^{s f}$ as well as $\varsigma_{q}^{s f}$ and $\Delta T$ are negligible, the model becomes symmetric and the conventional stator-fieldoriented control strategy can be used [1]. If we consider that the stator flux and the electromagnetic torque are taken as control references, we get the following model from [(20), (24), and (25)].

$$
\begin{aligned}
i_{s d 1}^{s f *} & =\frac{\left(\tau_{r} s+1\right) \phi_{s 1}^{*}+\tau_{r} \sigma_{d} L_{s d} i_{s q 1}^{s f *} \omega_{s l}}{\left(1+\sigma_{d} \tau_{r} s\right) L_{s d}} \\
i_{s q 1}^{s f *} & =\frac{T_{e}^{*}}{n_{p} \phi_{s 1}^{*}} \\
\omega_{s l}^{*} & =\frac{\frac{L_{s d}}{\tau_{r}}\left(1+\sigma_{d} \tau_{r} s\right) i_{s q 1}^{s f *}}{\phi_{s 1}^{*}-\sigma_{d} L_{s d} i_{s d 1}^{s f *}}
\end{aligned}
$$

where $s$ is the differential operator $(=d / d t)$.

We demonstrate now that the current $i_{s q 1}$ and the slip angular frequency have equivalent roles. By using (3)-(6), we can establish expressions of the electromagnetic torque as a function of the slip angular frequency

$T_{e}=n_{p} \phi_{s 1}^{2} \frac{\tau_{r}\left(1-\sigma_{d}\right)}{L_{s q}\left[\left(1+\tau_{r} \sigma_{q} s\right)\left(1+\tau_{r} \sigma_{d} s\right)+\sigma_{d} \sigma_{q}\left(\tau_{r} \omega_{s l}\right)^{2}\right]} \omega_{s l}$.

From (29), and by neglecting the term $\sigma_{d} \sigma_{q}\left(\tau_{r} \omega_{s l}\right)^{2}$, we obtain the following relation between electromagnetic torque and slip angular frequency.

$$
T_{e}=n_{p} \phi_{s 1}^{2} \frac{\tau_{r}\left(1-\sigma_{d}\right)}{L_{s q}\left(1+\tau_{r} \sigma_{q} s\right)\left(1+\tau_{r} \sigma_{d} s\right)} \omega_{s l} .
$$

With a constant flux, we can note from expression (30) that the electromagnetic torque is proportional to the slip angular frequency. However, the electromagnetic torque can be expressed with the slip angular frequency. If we consider that the stator flux and the slip angular frequency are taken as references of the control, we get the following model.

$$
\begin{aligned}
& i_{s d 1}^{s f *}=\frac{\left(\tau_{r} s+1\right) \phi_{s 1}^{*}+\tau_{r} \sigma_{d} L_{s d} i_{s q 1}^{s f *} \omega_{s l}^{*}}{L_{s d}\left(1+\sigma_{d} \tau_{r} s\right)} \\
& i_{s q 1}^{s f *}=\frac{\left(\phi_{s 1}^{*}-\sigma_{d} L_{s d} i_{s d 1}^{s f *}\right) \tau_{r} \omega_{s l}^{*}}{L_{s d}\left(1+\sigma_{d} \tau_{r} s\right)} .
\end{aligned}
$$

\section{SENSORLESS SPEEd CONTROL AlgORITHM}

A new approach to estimate speed is presented in [18]. The strategy of this method is based on the calculation of slip angular frequency, which enables us to determine the estimated rotor angular frequency. The proposed method for rotor speed estimation is based only on measurement of the main and the auxiliary windings stator currents and the reference $q$-axis current generated by the algorithm of ISFOC.

From (31) and (32), we obtain the following relation between slip angular frequency and $q$-axis stator current.

$$
i_{s q 1}^{s f *}=\frac{\left(1-\sigma_{d}\right) \tau_{r} \phi_{s 1}^{*}}{L_{s d}\left[\left(1+\sigma_{d} \tau_{r} s\right)^{2}+\left(\tau_{r} \sigma_{d} \omega_{s l}^{*}\right)^{2}\right]} \omega_{s l}^{*} .
$$

From (33), and by neglecting the term $\left(\tau_{r} \sigma_{d} \omega_{s l}^{*}\right)^{2}$, we obtain the following relation between slip angular frequency and $q$-axis stator current.

$$
\omega_{s l}^{*}=\frac{L_{s d}\left(1+\sigma_{d} \tau_{r} s\right)^{2}}{\left(1-\sigma_{d}\right) \tau_{r} \phi_{s 1}^{*}} i_{s q 1}^{s f *} .
$$

From (34), it may be noted that the slip angular frequency is represented by second-order differential equation $q$-axis current. Therefore, it is possible to estimate the slip angular frequency using the regulation in closed-loop $q$-axis current. For that, we will study the influence of slip angular frequency on the $q$-axis current. Using (32), we obtain the following $q$-axis reference current with stator flux reference and slip angular frequency estimation.

$$
s i_{s q 1}^{s f *}=-\frac{1}{\sigma_{d} \tau_{r}} i_{s q 1}^{s f *}+\frac{\phi_{s 1}^{*}}{\sigma_{d} L_{s d}} \widehat{\omega}_{s l}-\widehat{\omega}_{s l} i_{s d 1}^{s f *} .
$$




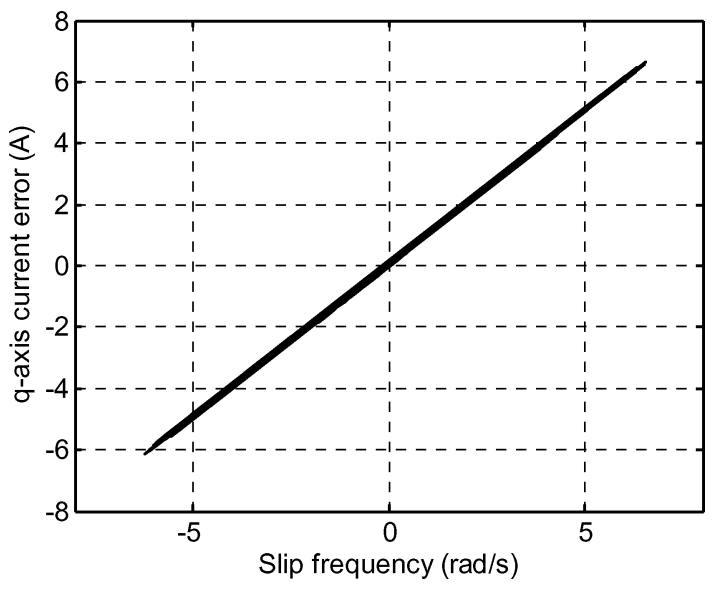

Fig. 1. $q$-axis current error in relation with slip angular frequency.

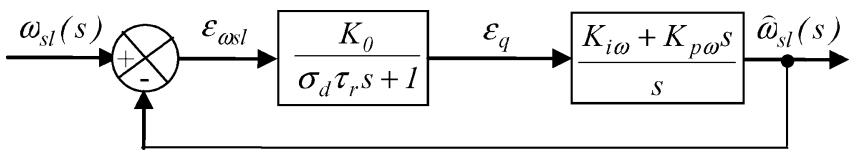

Fig. 2. Block diagram of slip angular frequency estimation.

The component error between measurement and reference $q$-axis currents is given by

$$
\varepsilon_{q}=i_{s q 1}^{s f *}-i_{s q 1}^{s f} \text {. }
$$

The slip angular frequency error is defined by

$$
\varepsilon_{\omega s l}=\omega_{s l}-\widehat{\omega}_{s l} .
$$

where $\widehat{\omega}_{s l}$ is the estimated slip angular frequency.

According to these errors (36) and (37), we express the measured and reference variable. Then, we replace them in (35), and by neglecting the term $\varepsilon_{d} \varepsilon_{w s l}$ we obtain the following expression.

$$
s \varepsilon_{q}=-\frac{1}{\sigma_{d} \tau_{r}} \varepsilon_{q}-\frac{\phi_{s 1}^{*}}{\sigma_{d} L_{s d}} \varepsilon_{\omega s l}+i_{s d 1}^{s f *} \varepsilon_{\omega s l} .
$$

Fig. 1 shows the evolution of the $q$-axis current error according to the slip angular frequency for a reference speed of $1500 \mathrm{r} / \mathrm{min}$ with nominal load torque applied to the motor at steady state. We note that there is a linear relationship between $q$-axis current error and slip angular frequency for whole range of operation. This result is justified by (34), and consequently we can use the $q$-axis current error to estimate slip angular frequency. From (38), we obtain the transfer function connecting the slip angular frequency error to the $q$-axis current error.

$$
\frac{\varepsilon_{q}(s)}{\varepsilon_{\omega s l}(s)}=\frac{K_{0}}{\sigma_{d} \tau_{r} s+1}
$$

where

$$
K_{0}=-\frac{\tau_{r}}{L_{s d}}\left(\phi_{s 1}^{*}-\sigma_{d} L_{s d} i_{s d 10}\right)
$$

with $i_{s d 10}$ is the steady state $d$-axis current.

To estimate the slip angular frequency, we used a proportional plus integral (PI) controller whose block diagram is represented by Fig. 2 .
From Fig. 2, the closed-loop transfer function can be represented in the following form.

$$
\frac{\widehat{\omega}_{s l}(s)}{\omega_{s l}^{*}(s)}=\frac{\omega_{0}^{2}}{s^{2}+2 \xi \omega_{0} s+\omega_{0}^{2}}\left(\frac{K_{p \omega}}{K_{i \omega}} s+1\right) .
$$

This expression is similar to a second order system with

$$
2 \xi \omega_{0}=\frac{K_{0} K_{p \omega}+1}{\sigma_{d} \tau_{r}} \quad \text { and } \quad \omega_{0}^{2}=\frac{K_{0} K_{i \omega}}{\sigma_{d} \tau_{r}}
$$

where $\omega_{0}$ and $\xi$ denote natural frequency and damping ratio, respectively.

The calculation of the parameters $K_{i \omega}$ and $K_{p \omega}$ of the PI regulator is based on the choice of the kind of response of the system obtained by imposing the natural frequency and the damping ratio.

In our application, we determine the parameters of the PI controller to obtain a response without overshoot $(\xi=1)$. Thus, the parameters of the PI controller are given by

$$
\begin{aligned}
K_{i \omega} & =\frac{\sigma_{d} \tau_{r}\left(\frac{k_{c}}{T_{r}}\right)^{2}}{K_{0}} \\
K_{p \omega} & =\frac{2 \sigma_{d} \tau_{r} \xi\left(\frac{k_{c}}{T_{r}}\right)-1}{K_{0}}
\end{aligned}
$$

where $T_{r}$ is defined as the time required for the step response to rise from $5 \%$ of the steady state value to $95 \%$ of the steady state value and $k_{c}$ is a constant obtained by the relation $\omega_{0} T_{r}=k_{c}$. For a damping ratio $\xi=1$, the value of the constant $k_{c} \approx 4.75$. The PI controller gains for the estimated slip angular frequency are given in Table II.

According to (34), the accuracy of slip angular frequency estimation of an induction motor speed sensor can be affected by rotor resistance variation during operation. Specially, at very low speed, ISFOC of SPIM is particularly sensitive to the rotor resistance error.

Fig. 3 represents the block diagram of speed sensorless ISFOC for SPIM drive.

In this study, integral plus proportional (IP) speed controller is used instead of the PI speed controller. The reason is that the zero introduced in the closed loop transfer function by the PI speed controller does not appear in the case of the IP speed controller. Therefore, the IP speed controller used here leads to a response without overshoot results for a step change in speed reference with damping ratio $\xi=1$.

\section{EXPERIMENTAL IMPLEMENTATION}

To check the performance of the proposed method, a prototype implementation of the sensorless ISFOC of a SPIM drive was carried out. Simulation and experimental tests were carried out based only on the estimation scheme for sensorless ISFOC of a SPIM drive is proposed in Fig. 3. The scheme used for the experimental setup is shown in Fig. 4.

The experimentation has been carried out using MATLABSimulink and dSPACE DS1104 real-time controller board. This board contains a Motorola Power PC 603e model that operates at the speed of $250 \mathrm{MHz}$ and a DSP (TMS320F240-20 MHz). 


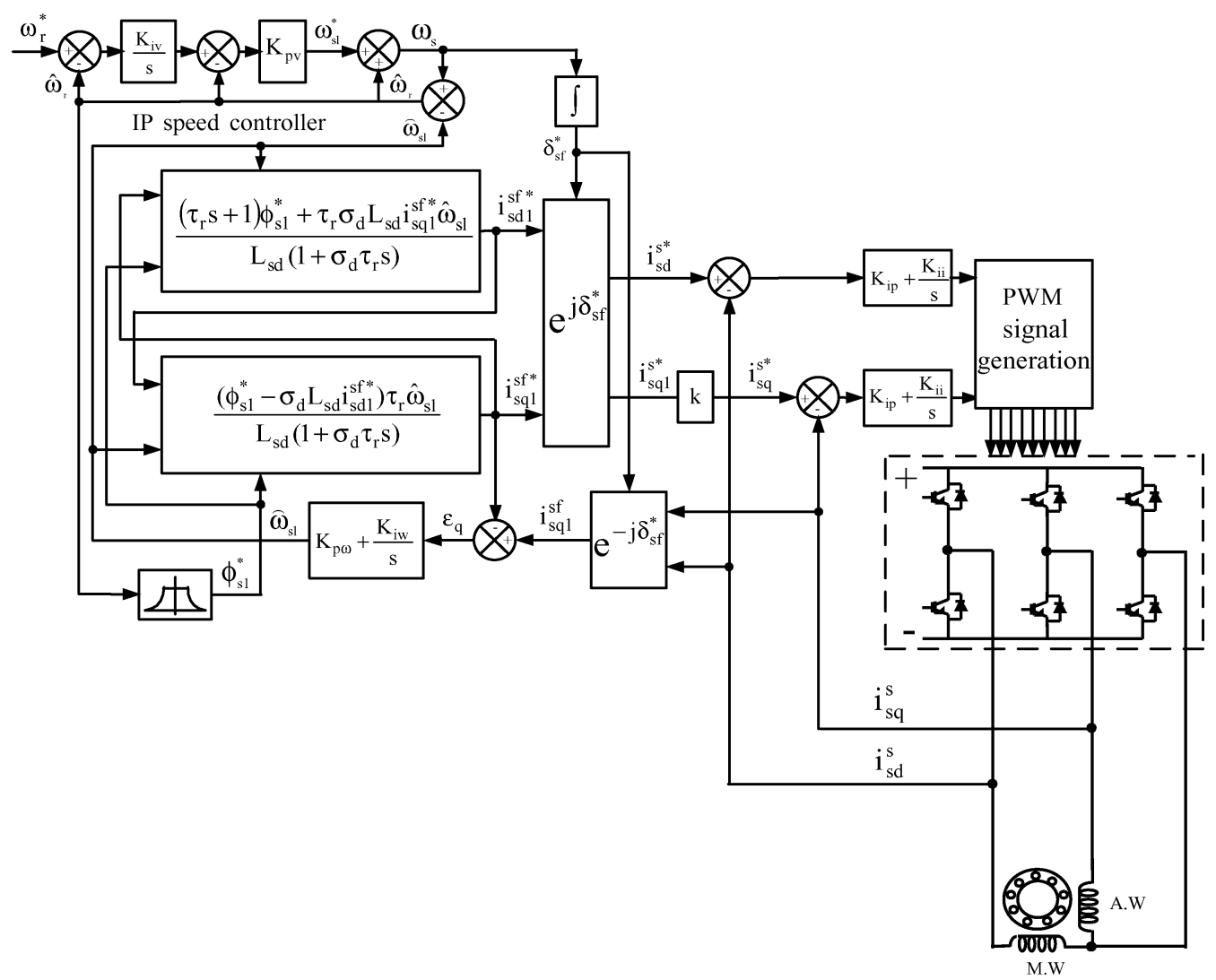

Fig. 3. Block diagram of speed sensorless ISFOC for SPIM drive.

The SPIM is fed by a three-leg voltage source inverter (VSI) using six insulate bipolar transistors. As shown in Fig. 4, the one end of the main and auxiliary windings of motor are connected to one half bridge each. The other ends are tied together and connected to the third half bridge. With this drive topology, control becomes more efficient but the control algorithm becomes more complex. The winding voltages should be controlled to achieve the phase difference between the effective voltages across the main and auxiliary windings in order to have a $90^{\circ}$ phase shift to each other. The load is generated through a magnetic powder brake coupled to the SPIM.

To reduce the ripple current of the SPIM drive, we implement a suitable PWM for the three-leg two-phase output voltages inverter. We propose sinusoidal PWM method instead of space vector pulsewide modulation.

In three-leg inverter, two legs control the main and auxiliary winding of the SPIM voltages and one leg controls the offset voltage. In the experimental test, we realize PWM signals for three-leg two-phase inverter in the following way.

1) PWM duty cycle is calculated according to $v_{\text {sdref }}$ for $\operatorname{leg} 1$.

2) PWM duty cycle is calculated according to $v_{\text {sqref }}$ for leg 2.

3) Duty cycle is taken constant equal to 0.5 to provide a zero reference voltage for leg 3 .
Fig. 5 shows the photograph of the experimental test system using a $1.1 \mathrm{~kW}$ four-pole SPIM with parameters listed in Table I. The PI $d-q$ axis currents controller gains are listed in Table II.

Fig. 6 shows the simulation and experimental results obtained for a step reference speed $(1500 \mathrm{r} / \mathrm{min})$ with the proposed fieldoriented control strategy. A rotor speed reference of $1500 \mathrm{r} / \mathrm{min}$ is imposed with a load torque equal to $4 \mathrm{Nm}$ applied at $6 \mathrm{~s}$ and removed at $16 \mathrm{~s}$. Here, the reference stator flux is kept constant at the nominal value $0.8 \mathrm{~Wb}$. The gains of the IP speed controller, listed in Table II, are calculated by the same method as those of the PI controller with a damping ratio $\xi=1$.

Fig. 6(a) and (b) shows the reference, the estimated and the real rotor speed signals with the proposed FOC. Fig. 6(a) shows the speed response of the drive system at step reference speed $(1500 \mathrm{r} / \mathrm{min})$. The step reference speed is applied at $1 \mathrm{~s}$ without load, and we applied the load torque equal to $4 \mathrm{Nm}$ at $6 \mathrm{~s}$ and removed at $16 \mathrm{~s}$. Fig. 6(c) and (d) shows the waveforms of the estimation error obtained with the rotor speed controller implemented in the synchronous reference frame. It will be noticed that the estimated and the real rotor speed signals are very close.

The estimation error is then less $\pm 1 \%$ of the rotor speed reference. The results confirm the validity of the new rotor speed estimation method. Fig. 6(e) and (f) shows the torque responses when the rotor speed is fixed at $1500 \mathrm{r} / \mathrm{min}$. The electromagnetic torque is estimated using stator current measurement. 


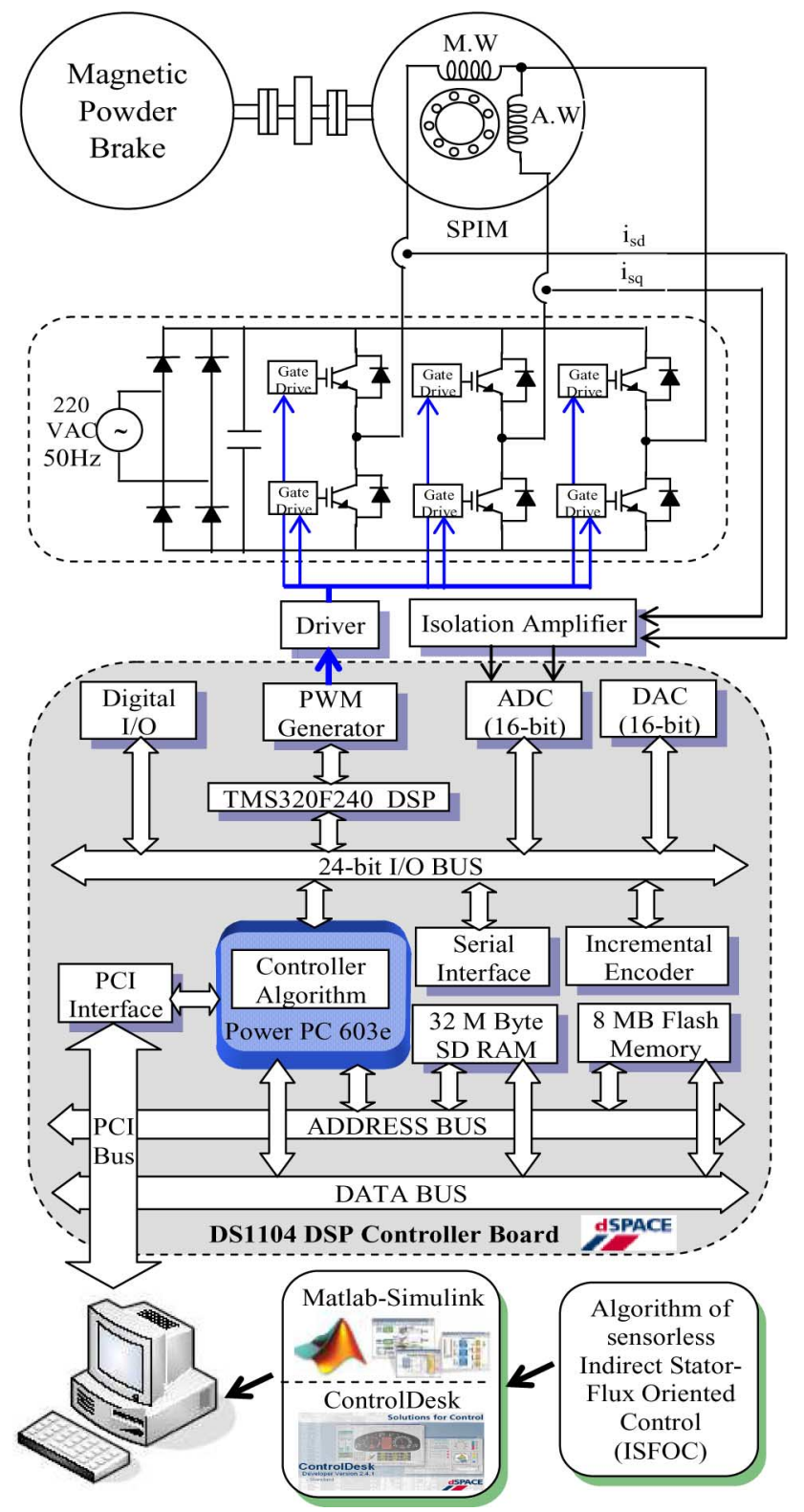

Fig. 4. Scheme used for experimental setup.

In Fig. 6(h), it is shown that the estimated $d$-axis flux has a small steady state error of about $2.5 \%$ when the load torque is applied.

In steady state operation, it should be noted that in Fig. 6(g) and (h) the stator flux is aligned with the $d$-axis $\left(\phi_{s d}=\phi_{s 1}\right.$ and $\phi_{s q}=0$ ) with a minor error due to the inaccuracy of the motor parameters. This shows that decoupling between stator flux and the torque is achieved.

In Fig. 6(i) and (j), simulation and experimental results of $d-q$ axis currents are presented. We also note that the $q$-axis current $i_{s q}$ is the same shape as the electromagnetic torque and the $d$-axis current $i_{s d}$ is similar to that of the stator flux. However, in this mode of operation, decoupled control of stator flux and torque is obtained, such that the stator flux magnitude is controlled by $d$-axis stator current and the torque is controlled by the $q$-axis stator current.

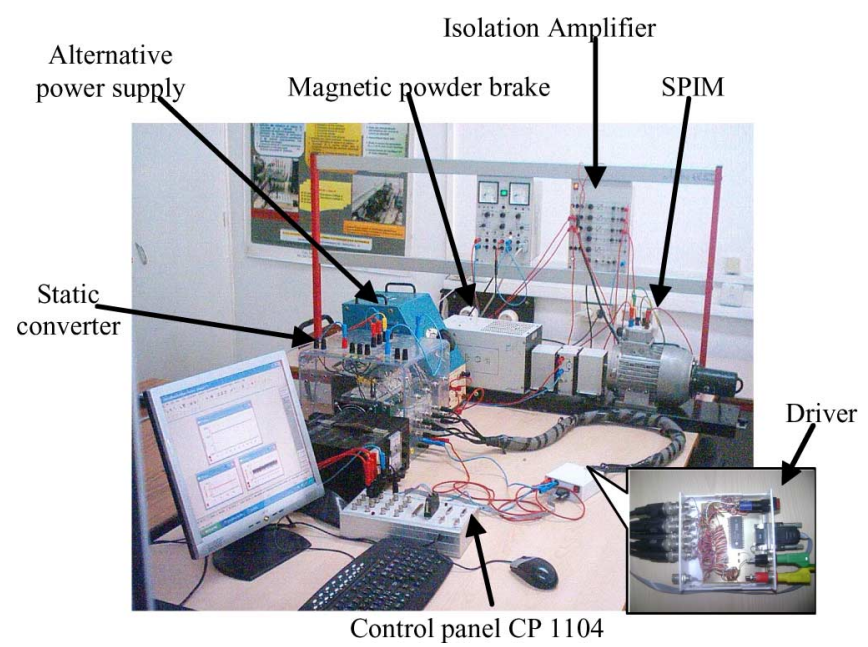

Fig. 5. Photograph of the experimental test system.

Fig. 7 shows the dynamic behaviour in the reversible operation from forward rated rotor speed $(1500 \mathrm{r} / \mathrm{min})$ to reverse rated rotor speed $(-1500 \mathrm{r} / \mathrm{min})$. The load torque equal to $4 \mathrm{Nm}$ was applied at $1 \mathrm{~s}$, and the estimated rotor speed coincides with the real rotor speed exactly even when the load torque is applied. Fig. 8 shows the rotor speed control performance in the low-speed operation region $(15 \mathrm{r} / \mathrm{min})$ of the rotor speed sensorless SPIM drive with a load torque of $1.5 \mathrm{Nm}$ is applied. It is shown that the proposed algorithm has good speed estimation and adequate vector control characteristics at low rotor speed operation.

However, we note that digital simulation and experimental results show an improved in performance of the proposed sensorless speed control algorithm.

In this paper, the estimated speed is obtained from only measurement of the main and the auxiliary windings stator currents and that of a reference $q$-axis current generated by the control algorithm. The rotor resistance variation produces an error of the $q$-axis current reference. Also, the calculation of the PI controller gains from (41) and (42) depends on the motor parameters and then it affects the estimate slip angular frequency estimation. For experimental implementation, the gains of the PI controller are adjusted in practice around the initial values obtained by (41) and (41) using the motor parameters given in appendix in Table I. The values of the PI controller gains for slip angular frequency are given in appendix in the Table II.

At very low speed and when the SPIM operates during a long time, stator resistance $R_{s d}, R_{s q}$ in two-phase induction motor varies. The slip angular frequency estimation is independent of stator resistances, but it depends on rotor resistance variation. It is known that rotor resistance variation leads to the largest speed estimation error, whereas stator resistance variation at low speeds significantly affects accuracy of stator field orientation and hence, dynamics of the drive. In this study, we considered that the stator and rotor resistances are constant, but a research tasks will be carried out to study the performances due to these variations. 
(a)

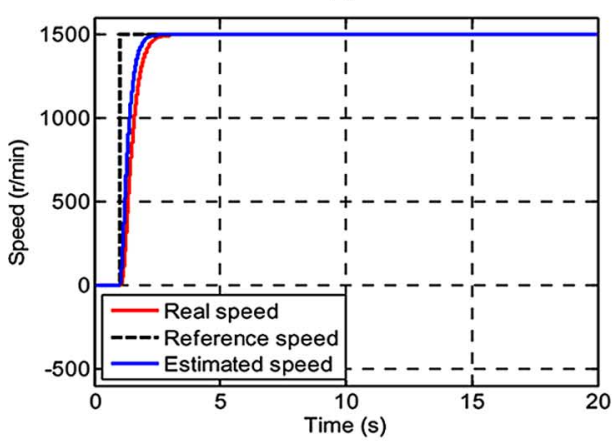

(c)

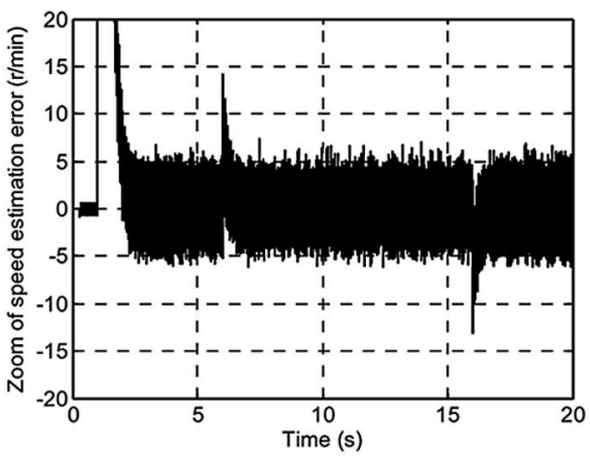

(e)

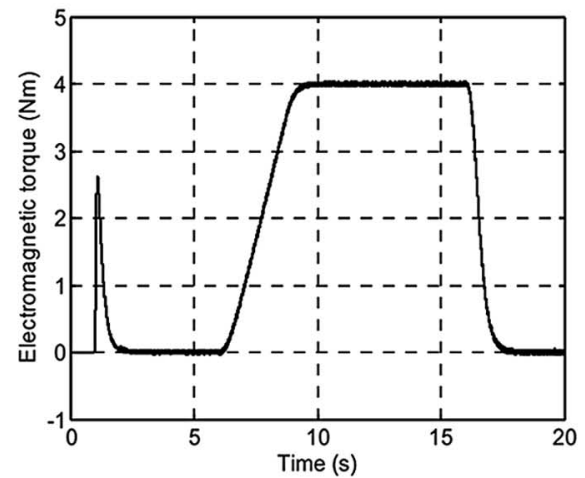

(g)

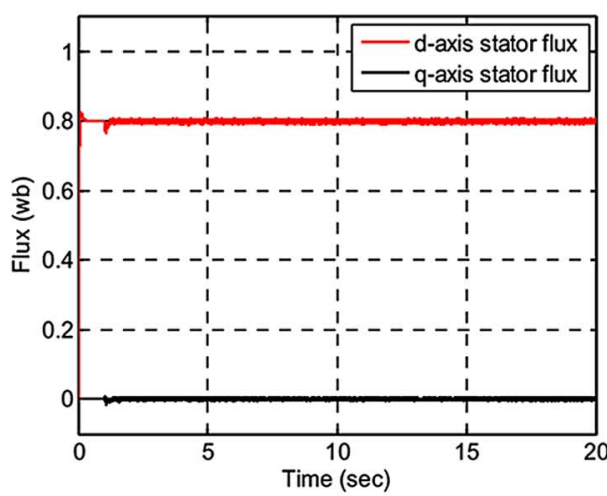

(b)

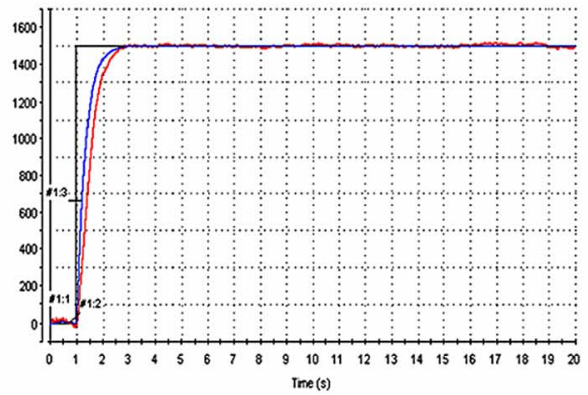

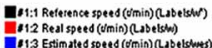

(d)
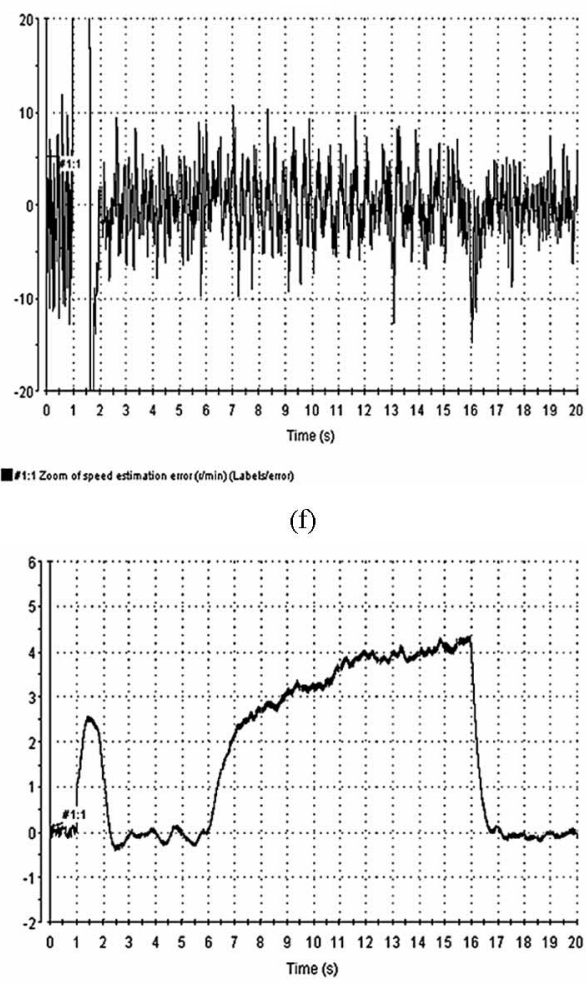

(h)

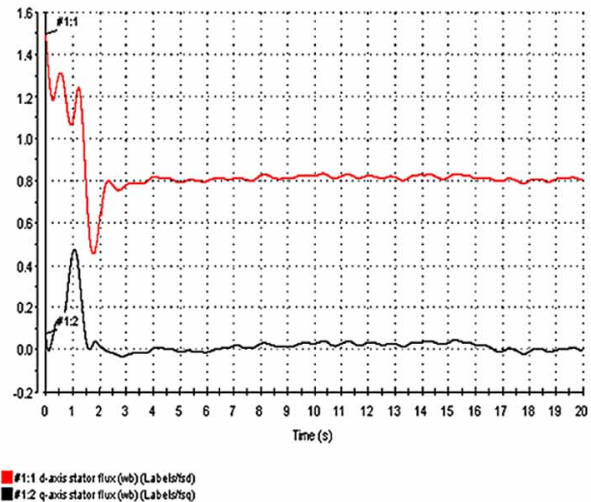

Fig. 6. Simulation and experimental results for a step reference speed ( $\omega_{r}^{*}=1500 \mathrm{r} / \mathrm{min}$ ). (a) Simulated. (b) Experimental. (c) Simulated. (d) Experimental. (e) Simulated. (f) Experimental. (g) Simulated. (h) Experimental. 
(i)

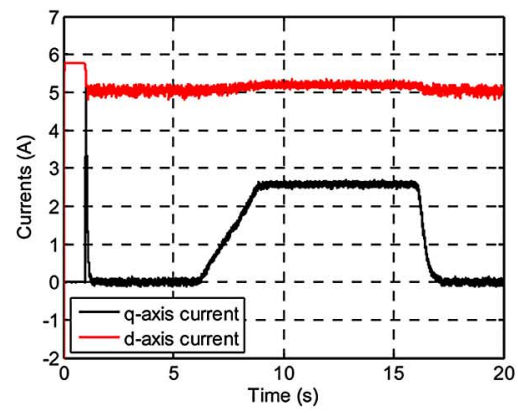

(j)

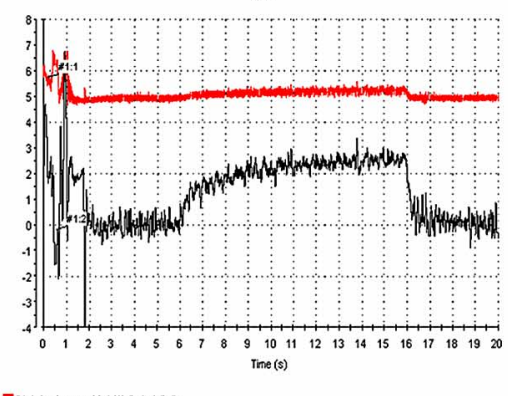

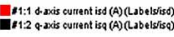

Fig. 6. (continued). Simulation and experimental results for a step reference speed ( $\left.\omega_{r}^{*}=1500 \mathrm{r} / \mathrm{min}\right)$. (i) Simulated. (j) Experimental.

(a)

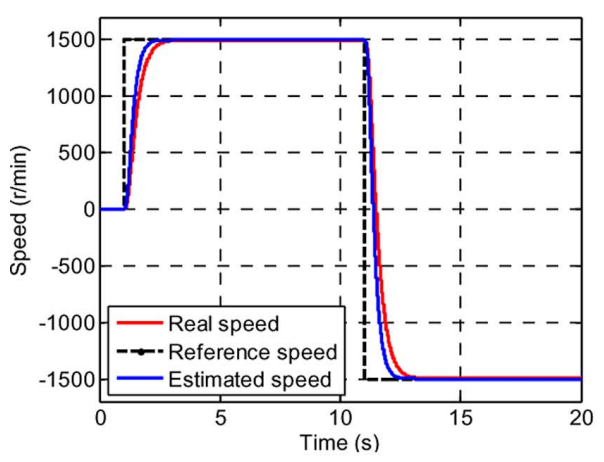

(c)

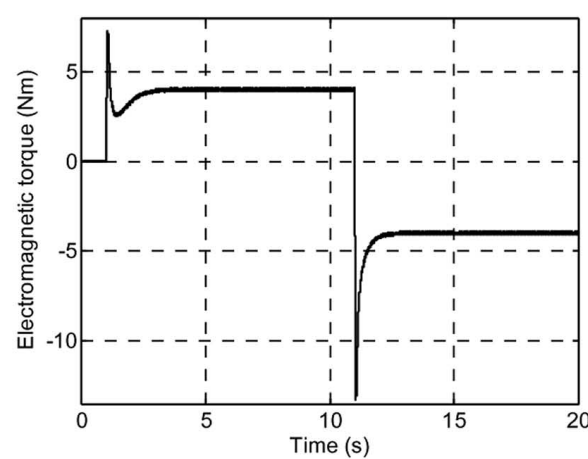

(b)

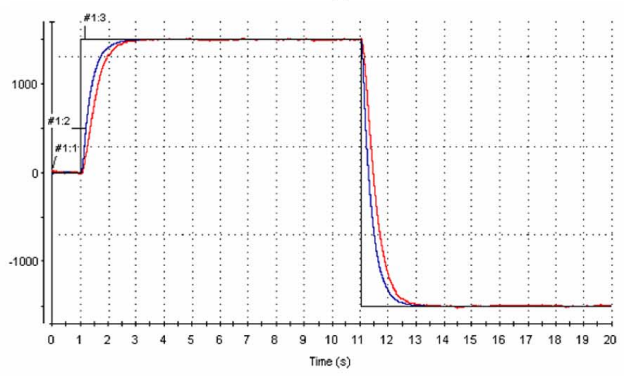

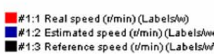

(d)

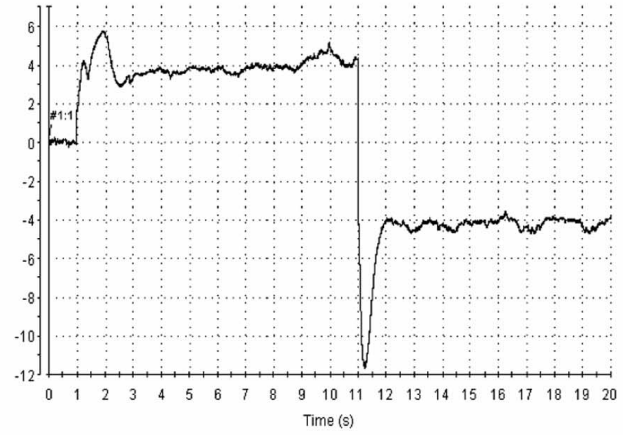

D/1:1 Electromagnetic torque (Nm) (Labelss'Cém)

Fig. 7. Simulation and experimental results for reversing speed reference from $\omega_{r}^{*}=1500 \mathrm{r} / \mathrm{min}$ to $\omega_{r}^{*}=-1500 \mathrm{r} / \mathrm{min}$. (a) Simulated. (b) Experimental. (c) Simulated. (d) Experimental.

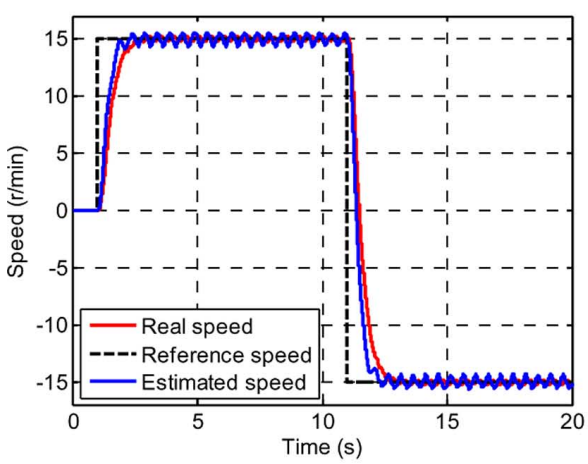

(b)

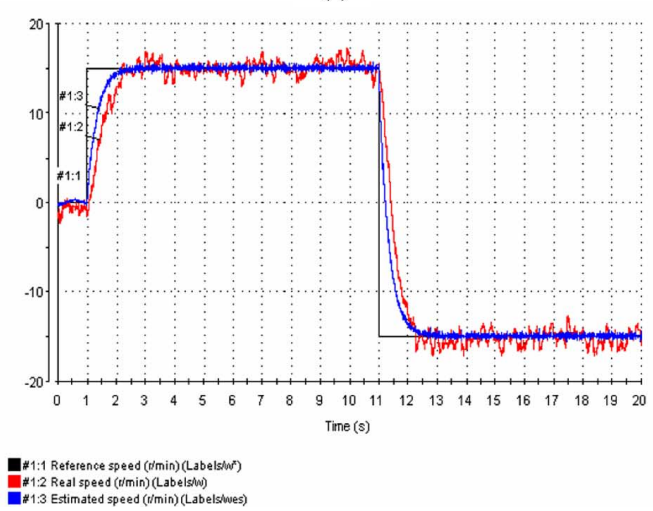

Fig. 8. Simulation and experimental results for reversing speed reference from $\omega_{r}^{*}=15 \mathrm{r} / \mathrm{min}$ to $\omega_{r}^{*}=-15 \mathrm{r} / \mathrm{min}$. (a) Simulated. (b) Experimental. 


\section{CONCLUSION}

In this paper, we have proposed a new approach for sensorless indirect stator field orientation speed control for SPIM fed by PWM three-leg two-phase VSI and verified it by experiments. The experimental results have shown that an adequate sensorless speed control of SPIM drive can be achieved at rated, low, and zero reference speed control.

The modeling approach proposed makes it possible to adapt some high-performance control strategies to be used with a single-phase motor drive system. This approach also provides a simple representation of the single-phase machine asymmetry, which is very useful for understanding some features of a singlephase drive system.

The proposed IP speed controller gave very satisfactory results in terms of load disturbance rejection and tracking rotor speed compared of the standard controller PI. It may be noted that the results obtained are satisfactory and the performance of the new approach for rotor speed estimation has been verified.

At very low and zero speed, sensorless speed ISFOC of SPIM drive is particularly sensitive to accurate stator and rotor resistance values. To overcome this problem, a study is to be conducted applying new techniques for online resistances estimation to improve and optimize the performances of sensorless ISFOC for a SPIM drive in steady-state, transient, low, and zero speed operation.

\section{APPENDIX}

TABLE I

SingLE-PHASE INDUCTION MOTOR PARAMETER

\begin{tabular}{lr|lc}
\hline $\mathrm{R}_{\mathrm{sd}}$ & $2.473 \Omega$ & Rated power & $1.1 \mathrm{~kW}$ \\
$\mathrm{R}_{\mathrm{sq}}$ & $6.274 \Omega$ & Rated voltage & $220 \mathrm{~V}$ \\
$\mathrm{R}_{\mathrm{r}}$ & $5.514 \Omega$ & Rated current & $5.1 \mathrm{~A}$ \\
$\mathrm{~L}_{\mathrm{sd}}$ & $0.0904 \mathrm{H}$ & Rated frequency & $50 \mathrm{~Hz}$ \\
$\mathrm{~L}_{\mathrm{sq}}$ & $0.1099 \mathrm{H}$ & Number of pole pairs & 2 \\
$\mathrm{~L}_{\mathrm{r}}$ & $0.0904 \mathrm{H}$ & Rated speed & $1430 \mathrm{r} / \mathrm{min}^{2}$ \\
$\mathrm{M}_{\text {srd }}$ & $0.0817 \mathrm{H}$ & $\mathrm{M}_{\text {srq }}$ & $0.0715 \mathrm{H}$ \\
$\mathrm{J}$ & $0.910^{-3} \mathrm{~kg} \cdot \mathrm{m}^{2}$ & $\mathrm{f}$ & 1.2 \\
\hline
\end{tabular}

TABLE II

GAINS OF DIFFERENT CONTROLLER

\begin{tabular}{l|ll|lr}
\hline PI d-q axis current controller & $\mathrm{k}_{\mathrm{ii}}$ & 30 & $\mathrm{k}_{\mathrm{ip}}$ & 5 \\
IP speed controller & $\mathrm{k}_{\mathrm{iv}}$ & 15 & $\mathrm{k}_{\mathrm{pv}}$ & 2 \\
PI slip angular frequency controller & $\mathrm{k}_{\mathrm{i} \omega}$ & 23 & $\mathrm{k}_{\mathrm{p} \omega}$ & 11 \\
\hline
\end{tabular}

\section{REFERENCES}

[1] M. R. Correa, C. B. Jacobina, A. M. N. Lima, and E. R. C. da Silva, "Rotor-flux-oriented control of a single-phase induction motor drive," IEEE Trans. Ind. Electron., vol. 47, no. 4, pp. 832-841, Aug. 2000.
[2] F. Blaabjerg, F. Lungeanu, K. Skaug, and M. Tonnes, "Two-phase induction motor drives," IEEE Trans. Ind. Appl. Mag., vol. 10, no. 4, pp. 24-32, Jul./Aug. 2004.

[3] T. A. Lettenmaier, D. W. Novotny, and T. A. Lipo, "Single-phase induction motor with an electronically controlled capacitor," IEEE Trans. Ind. Appl., vol. 27, no. 1, pp. 38-43, Jan./Feb. 1991.

[4] S. Reicy and S. Vaez-Zadeh, "Vector control of single-phase induction machine with maximum torque operation," in Proc. ISIE, 2005, vol. 3, pp. 923-928.

[5] M. R. Correa, C. B. Jacobina, E. R. C. D. Silva, and A. M. N. Lima, "Vector control strategies for single-phase induction motor drive systems," IEEE Trans. Ind. Electron., vol. 51, no. 5, pp. 1073-1080, Oct. 2004.

[6] M. Jemli, M. Boussak, M. Gossa, and M. B. A Kamoun, "Fail-safe digital implementation of indirect field oriented controlled induction motor drive," J. Simul. Practice Theory, vol. 8, pp. 233-252, Jun. 2000.

[7] M. Chomat and T.A. Lipo, "Adjustable-speed single-phase IM drive with reduced number of switches," IEEE Trans. Ind. Appl., vol. 39, no. 3, pp. 819-825, May/Jun. 2003.

[8] D. H. Jang and D. Y. Yoon, "Space-vector PWM technique for two-thase inverter-fed two phase induction motors," IEEE Trans. Ind. Appl., vol. 39, no. 2, pp. 542-549, Mar./Apr. 2003.

[9] M. A. Jabbar, A. M. Khambadkone, and Z. Yanfeng, "Space-vector modulation in a two-phase induction motor drive for constant-power operation," IEEE Trans. Ind. Electron., vol. 51, no. 5, pp. 1081-1088, Oct. 2004.

[10] M. B. R. Corrêa, C. B. Jacobina, A. M. N. Lima, and E. R. C. da Silva, "A three-leg voltage source inverter for two-phase AC motor drive systems," IEEE Trans. Power Electron., vol. 17, no. 4, pp. 517-523, Jul. 2002.

[11] D. H. Jang, "PWM methods for two-phase inverters," IEEE Trans. Ind. Appl. Mag., vol. 13, no. 2, pp. 50-61, Mar./Apr. 2007.

[12] H. Lu, W. Qu, X. Chen, Y. Fan, and X. Zhang, "A novel PWM technique with two-phase modulation," IEEE Trans. Power Electron., vol. 22, no. 6, pp. 2403-2409, Nov. 2007.

[13] R. Gurunathan and A. K. S. Bhat, "Zero-voltage switching DC link singlephase pulsewidth-modulated voltage source inverter," IEEE Trans. Power Electron., vol. 22, no. 5, pp. 1610-1618, Sep. 2007.

[14] M. B. R. Corrêa, C. B. Jacobina, P. M. dos Santos, E. C. dos Santos, and A. M. N. Lina, "Sensorless IFOC for single-phase induction motor drive system," in Proc. EEE Int. Conf. Electr. Mach. Drives, 2005, pp. 162-166.

[15] S. Vaez-Zadeh and A. Payman, "Design and application of speed estimation for single-phase induction motors," in Proc. EPE 2003, Toulouse, France, pp. 1-10.

[16] A. Payman and S. Vaez-Zadeh, "DSP based speed estimation of single phase induction motors," in Proc. IEEE Power Electron. Spec. Conf., 2004, vol. 2, pp. 1335-1340.

[17] S. Vaez-Zadeh and A. Payman, "Design and analysis of sensorless torque optimization for single phase induction motors," in Proc. Int. J. Energy Conver. Manage., 2006, vol. 47, pp. 1464-1477.

[18] M. Boussak and K. Jarray, "A high-performance sensorless indirect stator flux orientation control of induction motor drive," IEEE Trans. Ind. Electron., vol. 53, no. 1, pp. 41-49, Feb. 2006.

[19] R. Cardenas, R. Pena, J. Clare, G. Asher, and J. Proboste, "MRAS observers for sensorless control of doubly-fed induction generators," IEEE Trans. Power Electron., vol. 23, no. 3, pp. 1075-1084, May 2008.

[20] S. Bolognani, L. Peretti, and M. Zigliotto, "Parameter sensitivity analysis of an improved open-loop speed estimate for induction motor drives," IEEE Trans. Power Electron., vol. 23, no. 4, pp. 2127-2125, Jul. 2008.

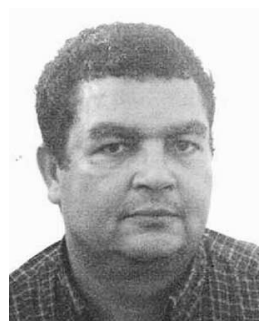

Mohamed Jemli was born in Nasr'Allah, Tunisia, on November 2, 1960. He received the B.S. and D.E.A. degrees from the Ecole Supérieure des Sciences et Techniques de Tunis (ESSTT), Tunis, Tunisia, in 1985 and 1993, respectively, and the Ph.D. degree from the Ecole Nationale d'Ingénieurs de Tunis (ENIT), Tunis, in 2000, all in electrical engineering.

From 1998 to 2001, he was an Aggregate Teacher at the Institut Supérieur des Etudes Technologiques (ISET) de Radès. Since 2001, he has been an Assistant Professor at the ESSTT. He has authored or coauthored more than 40 papers published in international conference proceedings and technical journals in the area, and also holds many patents. His current research interests include electrical machines, sensorless vector control of ac motor drives, and advanced digital motion control. 


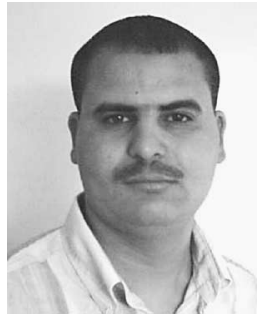

Hechmi Ben Azza was born in Bizerte, Tunisia, on July 5, 1978. He received the B.S. and Master's degrees in electrical engineering in 2002 and 2006, respectively, from the Ecole Supérieure des Sciences et Techniques de Tunis (ESSTT), Tunis, Tunisia, where he is currently working toward the Ph.D. degree.

His current research interests include electrical machines and sensor less vector control ac motor drives.

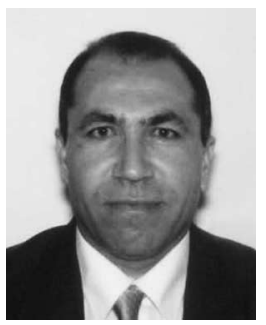

Mohamed Boussak (S'89-M'89-SM'06) was born in El Haouaria, Tunisia, on December 28, 1958. He received the B.S. and D.E.A. degrees from the Ecole Normale Supérieure de l'Enseignement Technique de Tunis (ENSET), Tunis, Tunisia, in 1983 and 1985, respectively, the Ph.D. degree from Pierre et Marie Curie University (Paris 6), Paris, France, in 1989, and the H.D.R. degree from Aix-Marseille III University, Marseille, France, in 2004, all in electrical engineering.

From September 1989 to September 1990, he was a Researcher with the Ecole Supérieure d'Ingénieurs de Marseille (ESIM), where he was an Associate Professor from October 1991 to June 2004. From October 1990 to September 1991, he was a Research Teacher in electrical engineering at Claude Bernard University, Lyon, France. From July 2004 to December 2008, he was an Associate Professor of electrical machines with the Ecole Centrale Marseille (ECM), France, where he has been a Senior Professor since January 2009. His current research interests include electrical machines, power conversion systems, sensorless vector control ac motor drives, advanced digital motion control, and diagnostics for industrial electric systems. He has authored or coauthored more than 80 papers published in scientific journals and conference proceedings in these research fields, and also holds many patents.

Dr. Boussak is a member of the IEEE Industry Application Society, the IEEE Industrial Electronics Society, and the IEEE Power Electronics Society. He is currently a member of the technical program committees of several international conferences and scientific journals in the areas of power electronics and motor drives fields.

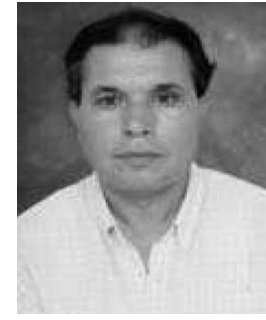

Moncef Gossa was born in Kairouan, Tunisia, on March 2, 1957. He received the B.S. and D.E.A. degrees from the Ecole Normale Supérieure de l'Enseignement Technique de Tunis (ENSET), Tunis, Tunisia, in 1981 and 1982, respectively, the $\mathrm{Ph} . \mathrm{D}$. degree from the Institut National des Sciences Appliquées, Toulouse, France, in 1984, and the H.D.R. degree from the Ecole Nationale d'Ingénieurs de Tunis (ENIT), Tunis, in 2004, all in electrical engineering.

He is currently a Professor Academic at the Ecole Supérieure des Sciences et Techniques de Tunis (ESSTT), Tunis. He is also the Director of the Institut Supérieur des Etudes Technologiques (ISET) de Radès, and the Unité de Recherche en Commande, Surveillance et Sûreté de Fonctionnement des Systèmes (C3S). He has authored or coauthored more than 60 papers published in international conference proceedings and technical journals in the areas, and also holds many patents. His current research interests include electrical machines, sensorless vector control ac motor drives, and diagnostics. 